\title{
Reabilitação dental com retentor intrarradicular - relato de caso clínico
}

\author{
Dental rehabilitation with intraradicular retainer - clinical case report \\ Rehabilitación dental con retenedor intrarradicular - reporte de caso clínico
}

Recebido: 15/10/2021 | Revisado: 22/10/2021 | Aceito: 22/10/2021 | Publicado: 24/10/2021

\author{
Sandreani da Silva Palheta \\ ORCID: https://orcid.org/0000-0002-1711-0084 \\ Centro Universitário Fametro, Brasil \\ E-mail: sandreanipalheta24@gmail.com \\ Géssica Vasconcelos da Silva \\ ORCID: https://orcid.org/0000-0001-6505-7487 \\ Centro Universitário Fametro, Brasil \\ E-mail: gessica.vasconcelos84@gmail.com \\ Thiago Mendes de Lima \\ ORCID: https://orcid.org/0000-0001-6524-3271 \\ Centro Universitário Fametro, Brasil \\ E-mail: thiago.lima@fametro.edu.br
}

\begin{abstract}
Resumo
Objetivo: O presente estudo relata um caso clínico de reabilitação do incisivo central superior esquerdo com uso de retentor intrarradicular pino de fibra de vidro, utilizando a técnica do pino anatômico com resina composta. Metodologia: Trara-se de um relato de caso clínico de cunho analítico descritivo (Pereira et al., 2018), realizado na clínica odontológica do CEUNI-Fametro, na disciplina de estágio supervisionado em Clínica Integrada II. Relato de caso clínico: A paciente melanoderma, R. R, de 43 anos, procurou atendimento, tendo como queixa principal o comprometimento da aparência estética do dente 21 ; relatou que comprometia seu sorriso e o incomodo. Nos exames clínico e radiográfico observou-se extensa destruição coronária e tratamento endodôntico insatisfatório. Foi planejado e realizado o retratamento endodôntico e a reabilitação com uso de retentor pré-fabricado pino de fibra de vidro. O pino de fibra de vidro foi condicionado com ácido fosfórico para limpeza da superfície, lavado com spray de ar e água, feito a secagem, preparado com silano, sistema adesivo e fotopolimerização. A resina composta foi depositada sobre o pino, levando ao conduto este lubrificado com gel hidrossolúvel, fazendo movimento de inserção e remoção, modelando o formato do conduto radicular. O cimento resinoso utilizado foi autoadesivo dual. A restauração da coroa clínica com resina composta com a técnica direta utilizando o protocolo de preparo para faceta e estratificação de cor. Considerações finais: $\mathrm{O}$ uso do pino de fibra de vidro mostrou-se uma alternativa eficaz na reabilitação do dente, favorecendo a estética da paciente, obtendo um resultado satisfatório.
\end{abstract}

Palavras-chave: Retentores intrarradiculares; Pino de fibra de vidro; Resina composta; Cimento resinoso.

\begin{abstract}
Objective: The present study reports a clinical case of rehabilitation of the upper left central incisor with the use of an intraradicular fiberglass post, using an anatomical post technique with composite resin. Methodology: This is a clinical case report of a descriptive analytical nature (Pereira et al., 2018), carried out in the dental clinic of CEUNIFametro, in the supervision discipline trained in Integrated Clinic II. Clinical case report: The patient Melanoderma, R. R, 43 years old, attended, whose main complaint was the impairment of the aesthetic appearance of tooth 21 ; he reported that it compromised his smile and bothered him. In clinical and radiographic clinics, extensive coronary destruction and unsatisfactory endodontic treatment were observed. Endodontic retreatment and rehabilitation using a prefabricated fiberglass post retainer was planned and carried out. The fiberglass post was conditioned with phosphoric acid for surface cleaning, washed with air and water spray, made dry, prepared with silane, adhesive system and light curing. The composite resin was deposited on the post, leading to the conduit lubricated with watersoluble gel, making insertion and removal movements, modeling the shape of the root canal. The resin cement used was dual self-adhesive. Restoration of the clinical crown with composite resin using the direct technique using the veneer preparation protocol and shade layering. Final considerations: The use of fiberglass post showed an effective alternative in tooth rehabilitation, favoring the patient's esthetics, obtaining a satisfactory result.
\end{abstract}

Keywords: Intraradicular retainers; Fiberglass pin; Composite resin; Resin cement.

\section{Resumen}

Objetivo: El presente estudio reporta un caso clínico de rehabilitación del incisivo central superior izquierdo con el uso de un poste de fibra de vidrio intrarradicular, utilizando una técnica de poste anatómico con resina compuesta. Metodología: Se trata de un caso clínico de carácter descriptivo analítico (Pereira et al., 2018), realizado en la clínica 
dental de CEUNI-Fametro, en la disciplina de supervisión capacitada en Clínica Integrada II. Reporte de caso clínico: Asistió el paciente melanoderma, R. R, de 43 años, cuyo principal síntoma fue la alteración del aspecto estético del diente 21; informó que comprometía su sonrisa y lo molestaba. En las clínicas clínicas y radiográficas se observó una extensa destrucción coronaria y un tratamiento endodóntico insatisfactorio. Se planificó y llevó a cabo un retratamiento y rehabilitación endodóntica mediante un retenedor de postes de fibra de vidrio prefabricado. El poste de fibra de vidrio se acondicionó con ácido fosfórico para limpieza de superficies, se lavó con aire y agua pulverizada, se secó, se preparó con silano, sistema adhesivo y fotopolimerización. La resina compuesta se depositó sobre el poste, conduciendo al conducto lubricado con gel soluble en agua, realizando movimientos de inserción y extracción, modelando la forma del conducto radicular. El cemento de resina utilizado fue autoadhesivo dual. Restauración de la corona clínica con resina compuesta mediante técnica directa mediante protocolo de preparación de carillas y estratificación de colores. Consideraciones finales: El uso de postes de fibra de vidrio mostró una alternativa eficaz en la rehabilitación dental, favoreciendo la estética del paciente, obteniendo un resultado satisfactorio.

Palabras clave: Retenedores intrarradiculares; Pasador de fibra de vidrio; Resina compuesta; Cemento de resina.

\section{Introdução}

Com o avanço dos materiais, equipamentos e exigência por procedimentos estéticos, o mercado odontológico tem buscado acompanhar essa tendência aprimorando suas técnicas e materiais restauradores, melhorando suas propriedades, proporcionando características o mais próximo possível da estrutura dental (Silva, Khan \& Pinho, 2020). Para reabilitação de dentes que sofreram grandes perdas teciduais dentárias no tratamento endodôntico se faz necessário o uso de um retentor intrarradicular. O primeiro relato do uso de retenção intrarradicular foi feito no século XVIII, em que Fauchard introduziu um pino de madeira no canal radicular para promover retenção da restauração, e a partir desta técnica, desenvolveram-se os Núcleos Metálicos Fundidos- NMF (Assunção, 2019).

A literatura apresenta diferentes materiais utilizados como retentores intrarradiculares, dentre eles o núcleo metálico fundido e os pré-fabricados metálicos e não metálicos (Borges \& Santos, 2019). Dentes tratados de modo endodôntico são reconhecidamente mais frágeis. A perda de dentina decorrente de fraturas, lesões cariosas e não cariosas e o tratamento endodôntico diminuem a resistência mecânica comparativamente com os dentes hígidos. Portanto, preservar ao máximo a estrutura dentária sadia faz parte do atual paradigma da odontologia e deve ser praticado por profissionais em todos os tratamentos (Baratieri, 2018). Existe uma variedade de pinos pré-fabricados com diferentes materiais, formato anatômicos e configurações de superfície. Da mesma maneira, inúmeros são os materiais e técnicas para a cimentação desses pinos e confecção de núcleos de preenchimento (Baratieri, 2018).

Os pinos de fibra de vidro têm sido uma excelente alternativa eletiva na reabilitação de dente tratado endodonticamente e têm se tornado comum na clínica diária por apresentarem propriedades semelhantes à estrutura dentinária, proporcionando modo de elasticidade semelhante ao da dentina, boa resistência, translucidez, o que permite uma transmissão de luz, demanda menor tempo clínico, proporciona menos desgaste de estrutura dental sadia, apresenta melhor distribuição de tensões à estrutura dentinária, diminuindo risco de fratura (Barbosa, 2016).

Contudo, quando deparamos com os condutos amplos, o uso de pino de fibra de vidro por si só com a cimentação pode ser crítico, pois demanda uma camada mais espessa de cimento resinoso, tornando-se mais passível a formação de bolhas e o aumento de tensão gerada na polimerização, causando linhas de fraturas, assim como comprometimento de força de união podendo levar o deslocamento do pino. Para resolução dessa falha e garantir maior a retenção nos condutos amplos, a anatomização de retentores intrarradiculares com resina composta se torna eficaz. A resina composta, por ser um material restaurador flexível e versátil, é uma alternativa viável na clínica diária, proporcionando a modelagem do canal e melhor adaptação do pino no interior do canal, pois a resina composta irá anatomizar a morfologia do interior do canal melhorando assim a retenção do material restaurador (Silva, Khan \& Pinho, 2020).

Vale ressaltar que as falhas podem acontecer em qualquer tipo de retentor intrarradicular se houver negligência do cirurgião dentista no decorrer das etapas na conduta clínica. É de extrema importância que o cirurgião dentista conheça e 
domine as técnicas e materiais disponíveis no mercado para então melhor indicar, mediante a análise, diagnóstico e planejamento, o material ideal para o tratamento reabilitador para a obtenção de um resultado satisfatório (Barbosa, 2016).

O presente trabalho tem como objetivo apresentar o relato de caso clínico de reabilitação de dente com retratamento endodôntico associado ao uso de pino de fibra de vidro anatomizado com resina composta.

\section{Metodologia}

Partindo da permissão da paciente por meio do Termo de Consentimento Livre e Esclarecido (TCLE) em partilhar sua imagem para devido fim, o presente estudo trata de um relato de caso clínico de cunho analítico descritivo (Pereira et al., 2018), realizado na clínica odontológica do CEUNI Fametro, na disciplina de estágio supervisionado em Clínica Integrada II, do curso de graduação do Centro Universitário Fametro.

\section{Relato de Caso}

Paciente sexo feminino, R. R, 43 anos, melanoderma, procurou atendimento na clínica odontológica do CEUNI Fametro, na disciplina de estágio supervisionado em Clínica Integrada II, do curso de graduação do Centro Universitário Fametro como queixa principal da aparência estética do incisivo central superior esquerdo (elemento 21) e vontade de recolocar seus dentes perdidos. Durante o exame clínico, observou-se extensa destruição coronária do incisivo central superior esquerdo nas faces vestíbulo palatino, durante a anamnese a paciente relatou que há um ano foi submetida a um tratamento endodôntico desse elemento, mas ele não foi restaurado (Figura 1)

Figura 1 - Elemento 21 com cavitação e tecido cariado na face vestíbulo palatino.

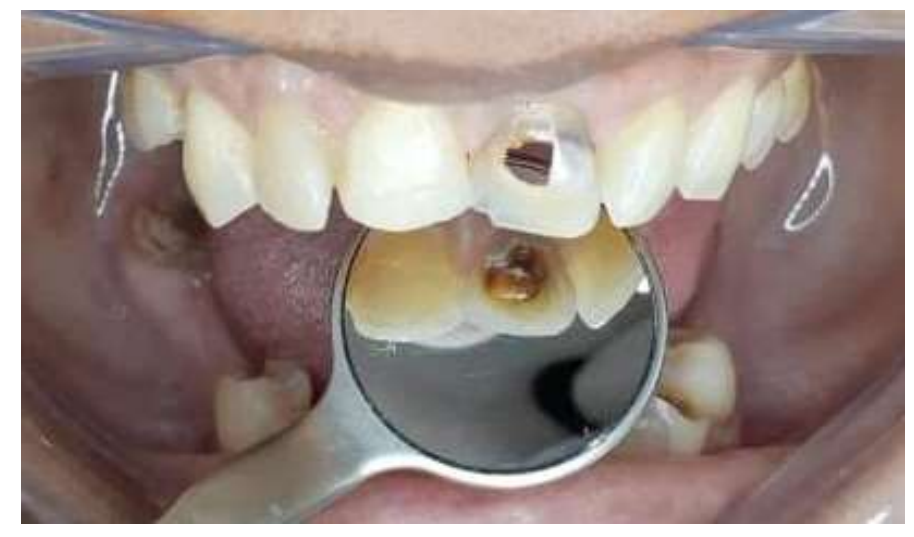

Fonte: Autores.

No exame clínico observou-se presença cálculo nos elementos 16,18,27,28, resto radicular do elemento 48, elemento 34 com destruição coronária nas faces oclusal, distal e vestibular, presença de toro palatino com queixa de trauma recorrente no palato. Ausência dos elementos 14,17,25,26,36,37,38,43,46,47. Após análise da radiografia periapical e o histórico da paciente, foi planejado para reabilitação dentária o retratamento endodôntico do elemento 21 (Figura 2), confecção de pino intrarradicular e reconstrução da coroa clínica com a técnica direta com resina composta, restauração do elemento 34, exodontia do resto radicular 48, remoção do tórus palatino e reabilitação com prótese parcial removível superior e inferior. Foi realizado a cirurgia remoção do tórus palatino, a exodontia do resto radicular 48, na clínica de cirurgia Bucomaxilofacial. 
Figura 2 - Radiografia periapical inicial do dente 21.

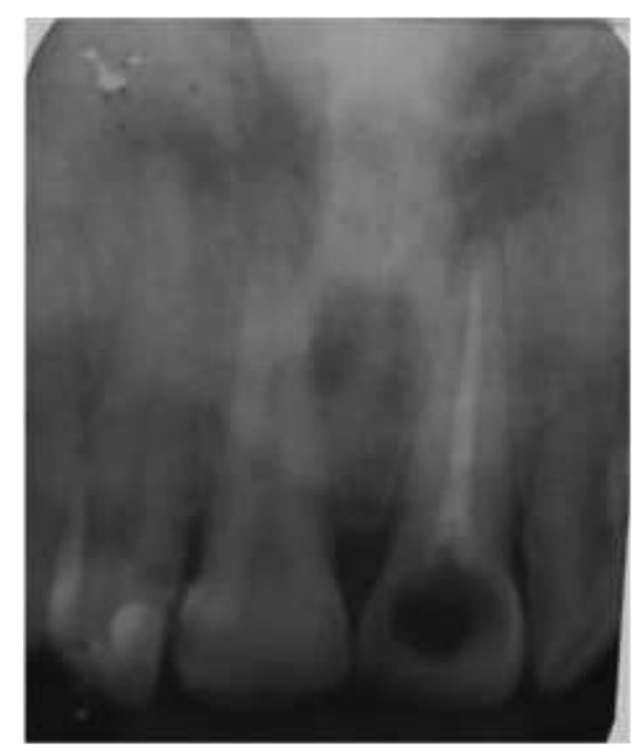

Fonte: Autores.

$\mathrm{Na}$ primeira sessão foi feita adequação do meio bucal com raspagem dos elementos com presença de cálculo e orientação de higiene oral. Na segunda sessão, sob isolamento absoluto, foi feita a remoção do tecido cariado com broca Carbide $\mathrm{n}^{\circ} 3$, a reconstrução provisória com resina composta da coroa clínica do elemento 21, para melhor suporte durante o retratamento endodôntico do elemento (Figura 3).

Figura 3 - Restauração provisória com resina composta.

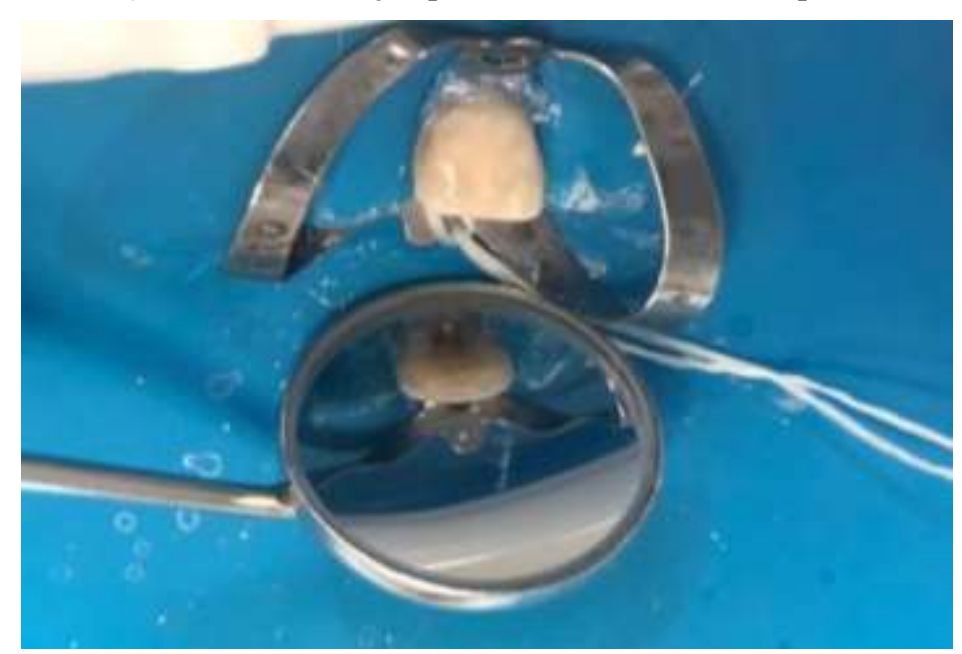

Fonte: Autores.

\subsection{Protocolo utilizado para retratamento endodôntico}

Para o retratamento endodôntico do incisivo central superior esquerdo (elemento 21), após tomada radiográfica, determinação do comprimento aparente do dente em 22mm (CAD, 2/3), foi realizada anestesia infiltrativa com lidocaína 2\% com epinefrina 1:100.000, feito o isolamento absoluto com disque de borracha, arco ostby, grampo 210. O tecido cariado já tinha sido removido anteriormente à restauração provisória do elemento deixando o preparo da embocadura do canal pronto. A antissepsia com a solução de gluconato de clorexidina 0,2\%, assim como substância química auxiliar para irrigação do canal, devido à paciente ser alérgica a hipoclorito de sódio. Iniciou- se a desobturação do canal utilizando as brocas Gattes Glidden 
n²,3 no terço cervical, seguindo para o esvaziamento do canal com o uso do motor endodôntico X-Smart Plus Maillefer (Dentsply Sirona ${ }^{\circledR}$ ), utilizando os instrumentos reciprocante da VDW Reciproc R25 e R50 a desobturação foi feita por terços, primeiro cervical, médio, e apical, alternando a lima manual e rotatória reciproc. Com leve pressão com a lima na embocadura do canal e seguindo a recomendação do fabricante com três movimento de bicada (para dentro e para fora do canal) e então retirada para fazer a limpeza do instrumento e irrigação do conduto (Figura 4).

Figura 4 - A) Irrigação com clorexidina 2\%; B) Desobturação do conduto com lima reciproc R25; C) Desobturação com a lima reciproc R50.

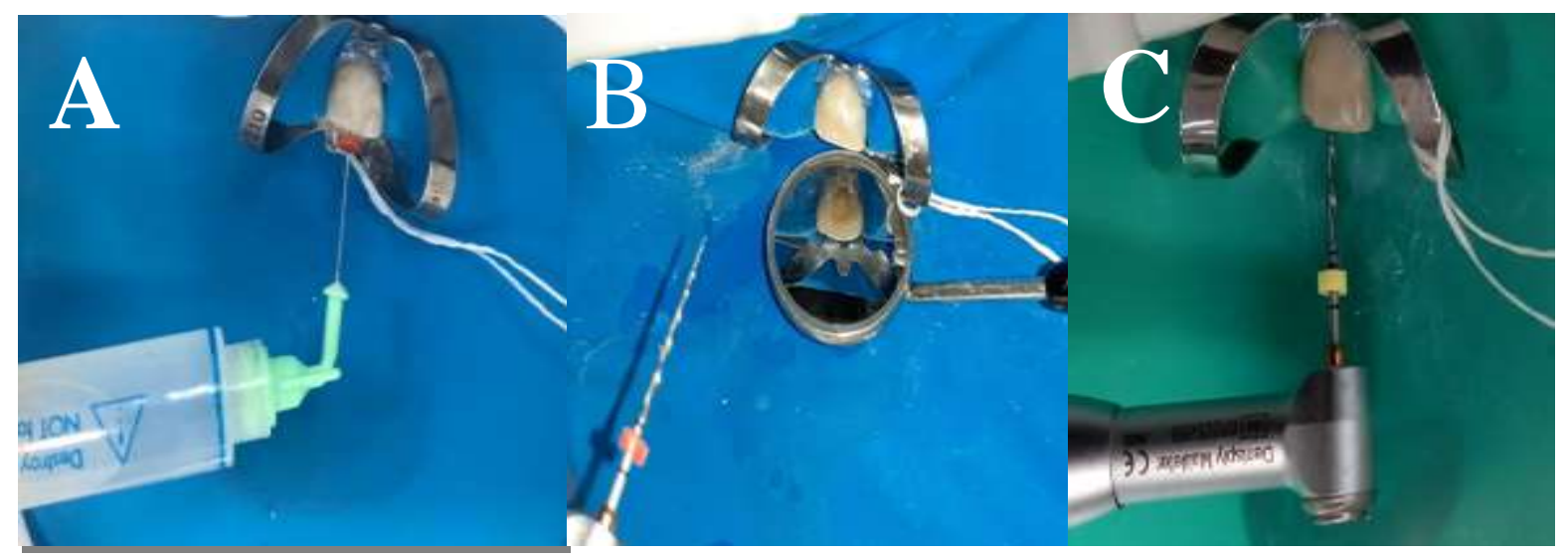

Fonte: Autores.

Posteriormente feito confirmação da odontometria com auxílio de um localizador foraminal obtendo o comprimento do real dente em 21mm, medicação intracanal pasta HPG (Hidróxido de cálcio, paramonoclofenol canforado e glicerina), selamento com cimento obturador provisório (cotozol@) e ionômero de vidro (ionoseal®), em uma outra sessão a remoção da medicação do canal, a recapitulação com a lima reciproc R50, para assepsia do canal ponta foi usada as ponta easy clean ( easy (®) acompanhada de irrigação com clorexidina 2\%, limpeza final com EDTA 17\%, seguida de clorexidina $2 \%$ e soro fisiológico 0,9\%, secagem do conduto com cone de papel absolvente estéril e finalização com a obturação do canal radicular em $21 \mathrm{~mm}$ com cimento endodôntico a base de hidróxido de cálcio (AH Plus®), mostrando-se satisfatória como mostra na imagem radiográfica (Figura 5). Procedimento realizado em três sessões, pelo fato do tempo levado para remoção do cimento e guta percha usada no tratamento anterior. 
Figura 5 - Radiografia periapical obturação em $21 \mathrm{~mm}$.

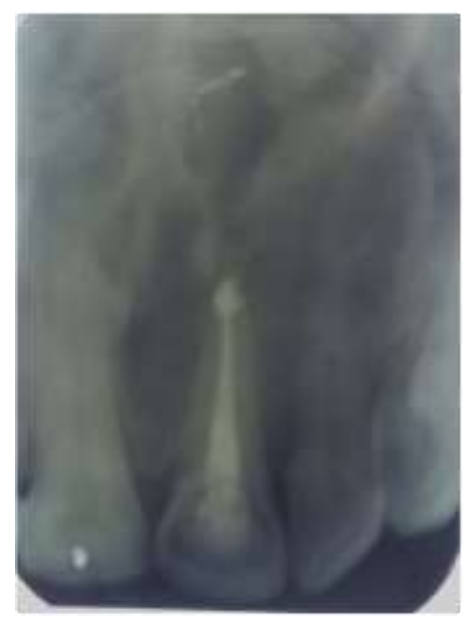

Fonte: Autores.

\subsection{Protocolo da cimentação do pino}

Para a reabilitação do elemento 21 a escolha do retentor intrarradicular foi utilizado o pino pré-fabricado de fibra de vidro optando pelo protocolo de confecção de pino anatômico, reembasado com resina composta. Inicialmente foi realizada a profilaxia com uso pedra pomes misturado com água, contra ângulo, escova de Robinson, pote dappen, Isolamento do Campo operatório, isolamento absoluto com o uso de dique de borracha (arco de Yong- Golgran, lençol de borracha, pinça porta grampo serrilhado tipo Palmer, alicate perfurador de Ainsworth, grampo 210, e amarrias com fio dental. Desobturação da restauração provisória palatino com o uso de caneta de alta rotação, ponta diamantada 1014 HL. O pino selecionado foi \#05 (White Post DC; FGM®), a desobturação do conduto para remoção da guta percha se deu com utilização das brocas de largo, números 2,3, calibrada com auxílio de uma régua milimetrada e stop de silicone, adaptada ao micromotor contra ângulo, na sequência para formatação do conduto com broca do pino selecionado no comprimento planejado em $17 \mathrm{~mm}$, restando $4 \mathrm{~mm}$ de obturação no canal, correspondendo $2 / 3$ do comprimento do dente. Em seguida a prova do pino avaliação visual e tátil para verificar o assentamento dentro do canal radicular quanto à sua adaptação em largura e comprimento. Sob irrigação com soro fisiológico $0,9 \%$, com agitação com escova profilática intracanal, foi feita a limpeza do canal. A secagem do conduto com cone de papel estéril (Figura 6). 
Figura 6 - A) Radiografia periapical da desobturação da guta percha, respeitando 4mm de vedamento; B) Prova do assentamento do pino; C) Limpeza do conduto com soro fisiológico e escova profilática intracanal; D) Secagem do conduto com cone de papel absorvente estéril.

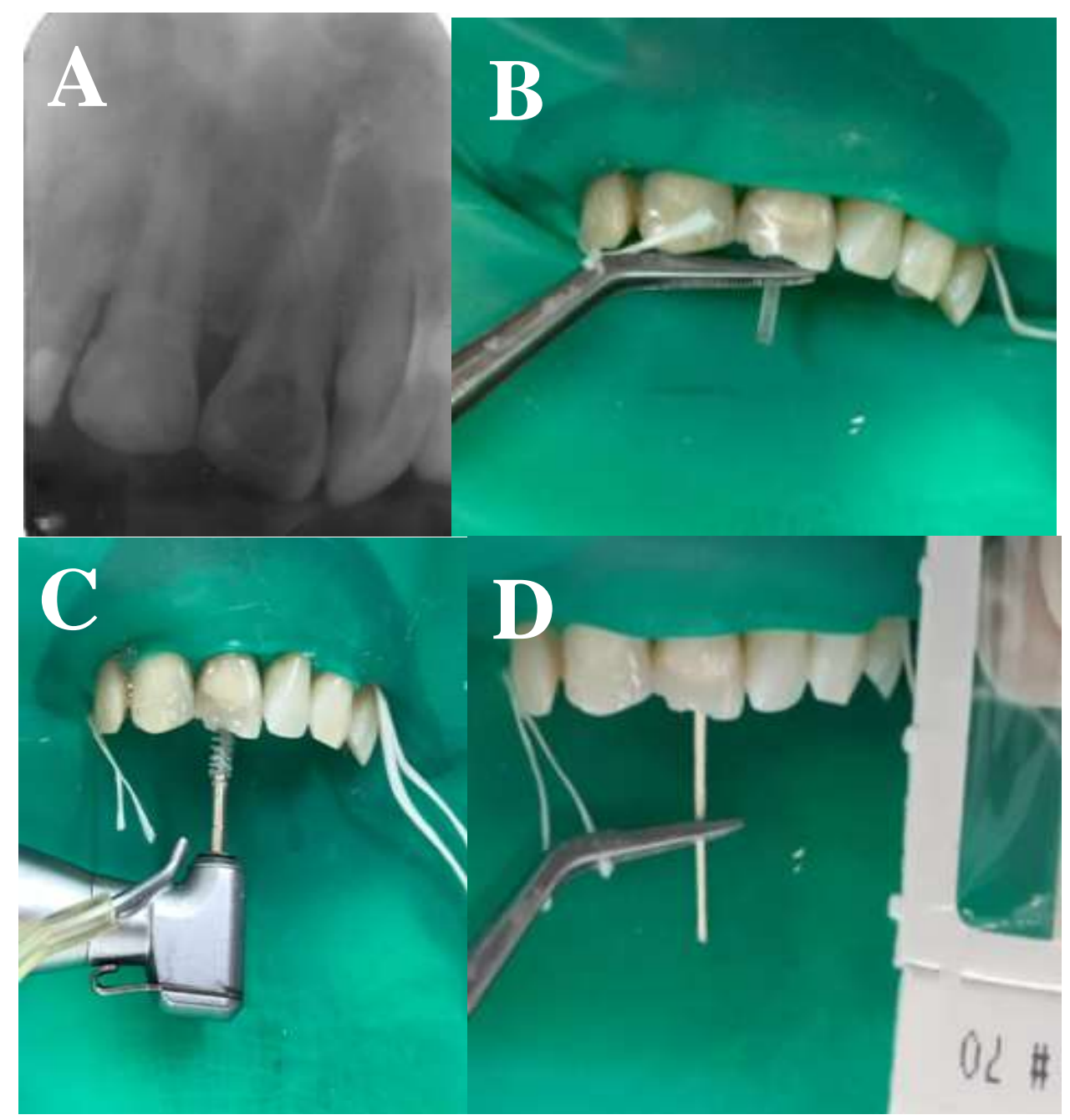

Fonte: Autores.

Foi feito também limpeza e tratamento da superfície do pino, condicionado com ácido fosfórico 37\% (Condac; FGM() por 20 segundos, para remoção de gordura e limpeza do pino, lavado com spray de água e seco com jato de ar.

Em seguida sinalização do pino com o uso do silano (angelus®), dupla aplicação sobre a superfície do pino (Figura 7), volatilizado com jato de ar em seguida aplicação do sistema adesivo (Ambar; FGM®) com esfregaço, seguido de jato de ar para remoção do excesso e volatilização, fotopolimerizado por 30 segundos com uso do fotopolimerizador (LED Radii -cal SDI®), (Figura 8). 
Figura 7 - Aplicação do silano.

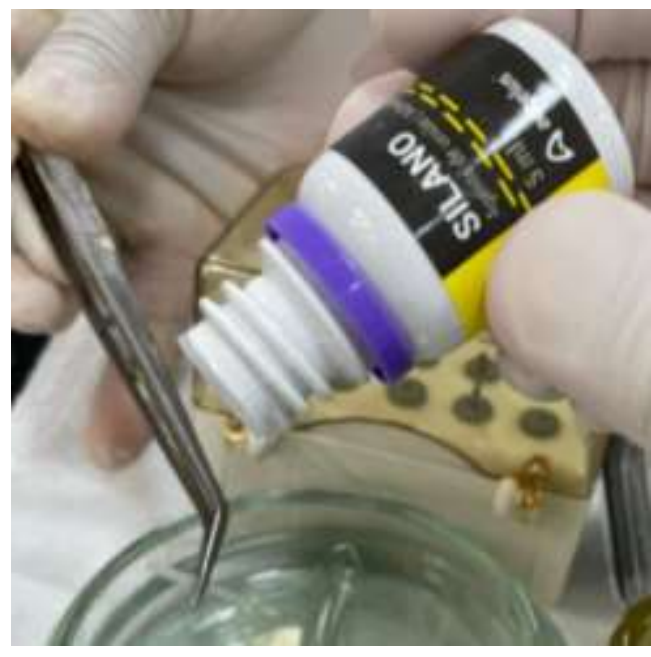

Fonte: Autores.

Figura 8 - A) Aplicação do sistema adesivo; B) Fotopolimerização.

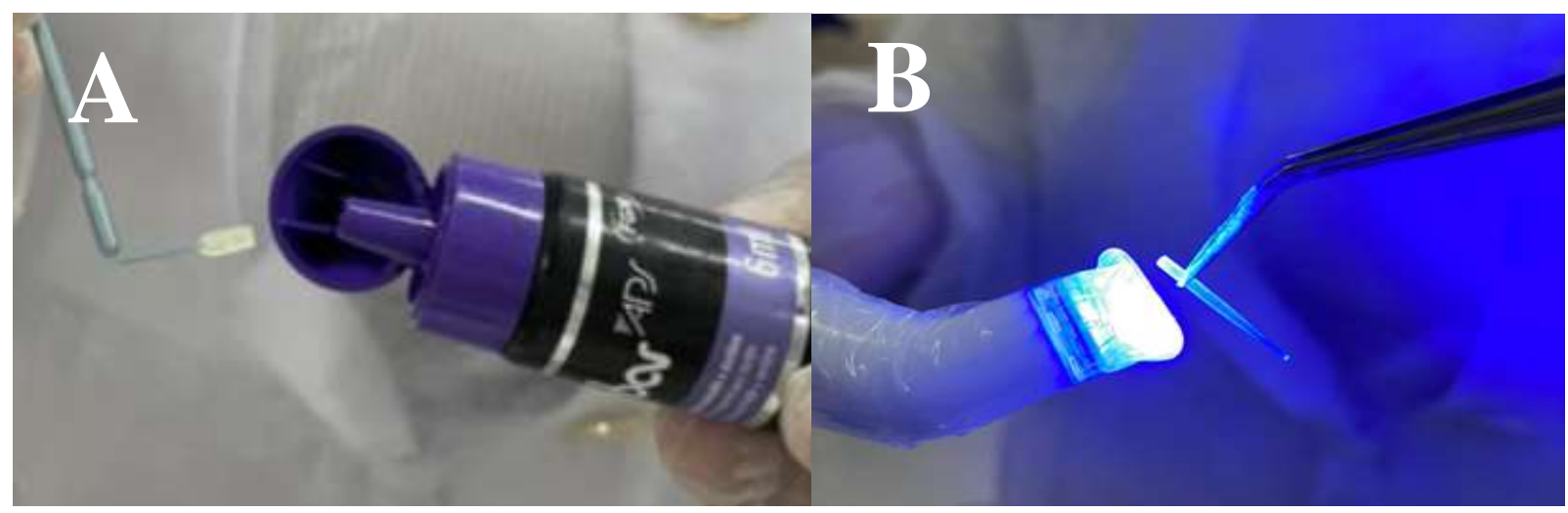

Fonte: Autores.

Em seguida foi feito adaptação da resina composta (3M ESPE Filtek; Z350 XT; cor B3B) no pino e modelagem dentro do canal este lubrificado com gel lubrificante hidrossolúvel (K-Y®), aplicado com o uso do microbrush, reembasando a estrutura anatômica do conduto, fotopolimerização por 60 segundos em posição.

Após remoção do conjunto a complementação da foto polimerização por mais 40 segundos, o pino anatômico foi levado em posição para verificar a adaptação no canal. Limpeza do conduto e remoção do gel lubrificante com irrigação com água e soro fisiológico $0,9 \%$, por 30 segundos, o conduto foi seco com ponta de papel absorvente estéril \#70(DENTPLY SIRONA®). A limpeza do pino anatômico com ácido fosfórico 37\%, aplicação do sistema adesivo, volatilização, secagem e foto polimerização da peça por 30 segundos.

A cimentação foi feita com cimento resinoso autoadesivo (Set PP SDI®), o qual foi aplicado no canal com adaptação da ponta intracanal. Em seguida a peça anatômica levada em posição e sobre leve pressão, foi feita a remoção do extravasamento do cimento com o uso de um aplicador descartável (microbrush) e fotopolimerizado por 40 segundos cada face, radiografia final. Após cimentação, foi condicionado a cavidade com ácido fosfórico 37\% (Condac; FGM®), feito a remoção com spray de ar e água, secagem, aplicação do adesivo (Ambar; FGM®), fotopolimerização por 30 segundos feita a restauração definitiva da face palatina com resina composta (3M ESPE Filtek; Z350 XT; cor B3B), fotopolimerizado por mais 30 segundos, em 
seguida foi feito o corte do pino com ponta diamantada 3118 em alta rotação com spray ar/ água, foi checado a oclusão da paciente, realizado o ajuste necessário (Figura 9).

Figura 9 - A) Adaptação da ponta intracanal; B) Aplicação do cimento no interior do conduto; C) Pino cimentado; D) Radiografia final do pino cimentado.

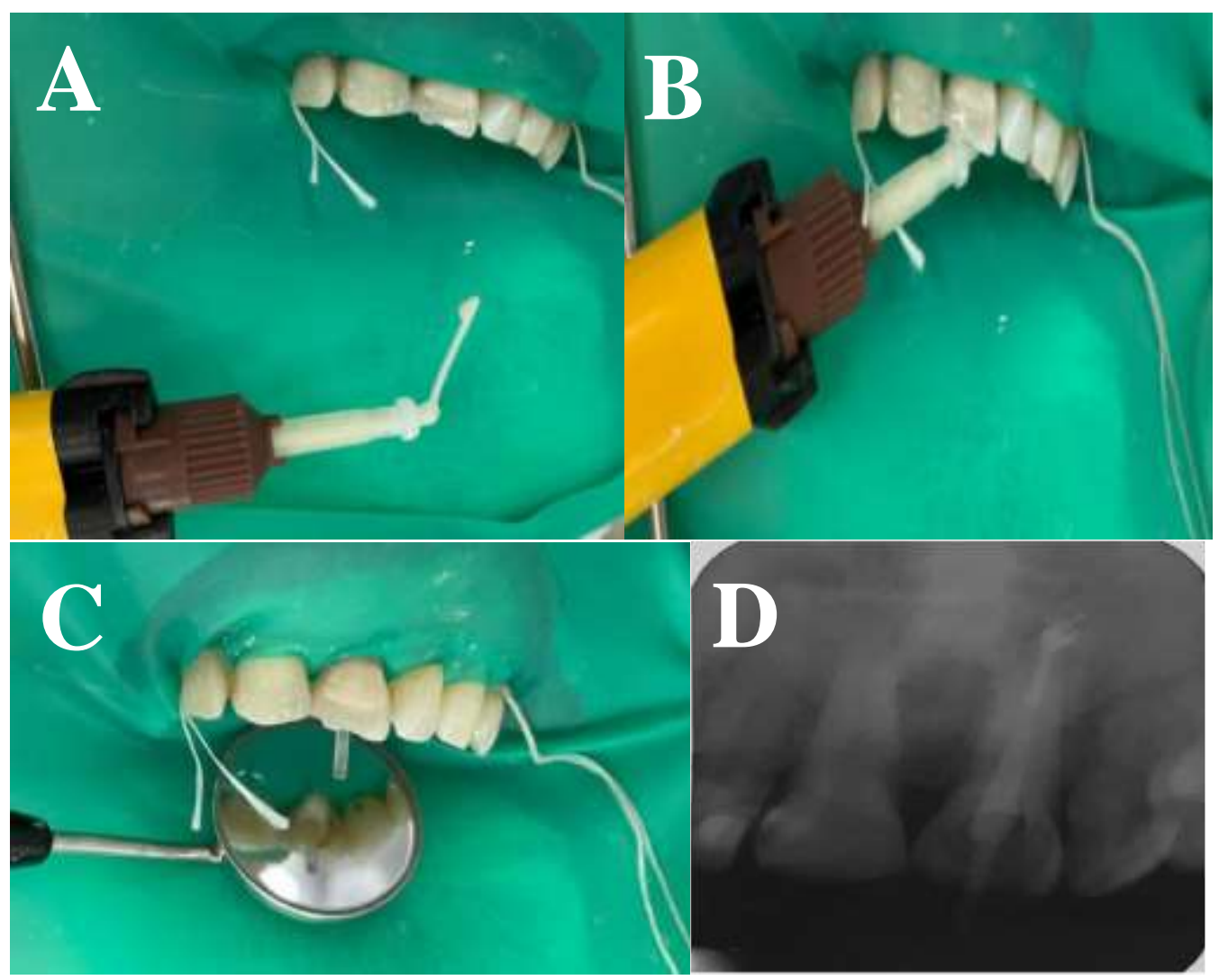

Fonte: Autores.

\subsection{Protocolo clínico das restaurações dos elementos 11 e 21.}

Na sequência, a reconstrução definitiva da coroa clínica dos elementos 11 e 21 com restauração em resina composta confeccionada segundo os princípios da técnica de estratificação natural. Seleção de cor da resina composta, as resinas selecionadas na cor DA3, DA2, EA2 (Vittra; FGM®), anestesia infiltrativa, profilaxia com uso pedra pomes misturado com água, contra ângulo, escova de Robson, pote dappen, Isolamento do Campo operatório, isolamento absoluto, técnica modificado com o uso de dique de borracha arco de Yong- (Golgran $\left.{ }^{\circledR}\right)$, lençol de borracha, pinça porta grampo serrilhado tipo Palmer, alicate perfurador de Ainsworth, grampos 209 em pré-molares em ambos os lados.

Foi utilizado o fio retrator de $n^{\circ} 0$ (Retraflex; biodinâmica $\left.{ }^{\circledR}\right)$. Para a confecção do preparo: caneta de alta rotação, com ponta diamantada $\mathrm{n}^{\mathrm{o}} 1012$ HL (American Burrs ${ }^{\circledR}$ ) fez-se a confecção da canaleta cervical; com a ponta diamantada tronco cônica $n^{\circ} 2135$, confecção de sulcos orientação e união total dos sulcos (Figura 10). 
Figura 10 - Preparo total.

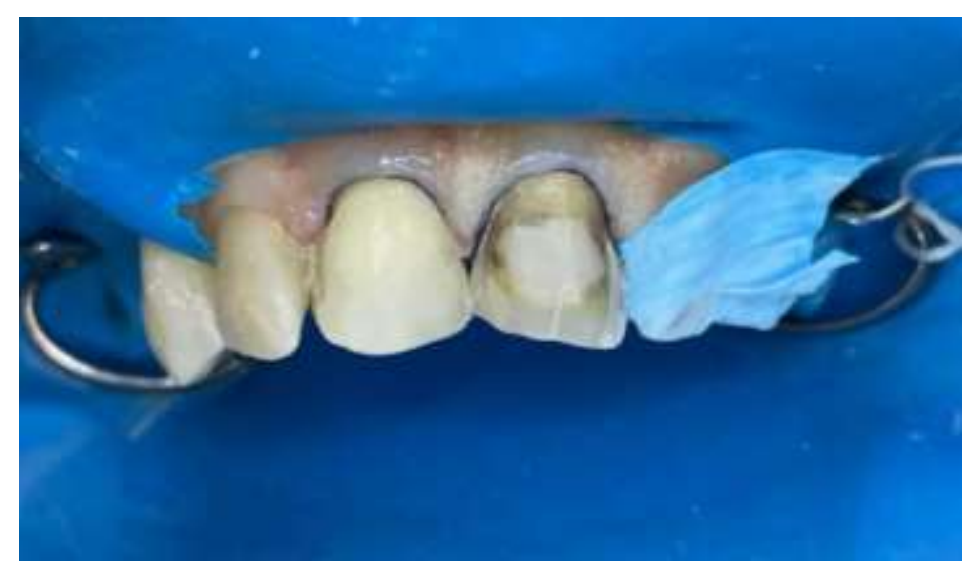

Fonte: Autores.

Condicionamento com ácido fosfórico 37\%(Condac;FGM ${ }^{\circledR}$ ), aplicado 15 segundos em dentina e 30 segundos em esmalte, remoção com jato de ar/água, secagem, aplicação do sistema adesivo (Ambar; FGM®), 2 vezes com esfregaço, volatilização com a seringa tríplice, fotopolimerização 30 segundos com uso do fotopolimerizador (LED Radii -cal SDI®), uso de fita matriz de poliéster (TDV®), com uso de espátula adequada para resina; seguindo a técnica estratificação natural do dente, foi feito o incremento da massa resina, respeitando a espessura adequada; com auxílio do pincel acomodação de cada incremento e fotopolimerizada por 30 segundos cada incremento; Acabamento com ponta diamantada 3195F,3195FF, disco de granulações grossa, média e fina (TDV®), lixa proximais de abrasividade de granulação média e fina.

Em uma outra sessão, foi realizado o polimento final com o uso Polidor Diamantado Composite (Jota®), (Figura 11)

Figura 11 - A) Restaurações com polimento final; B) Aspecto final do elemento 21.

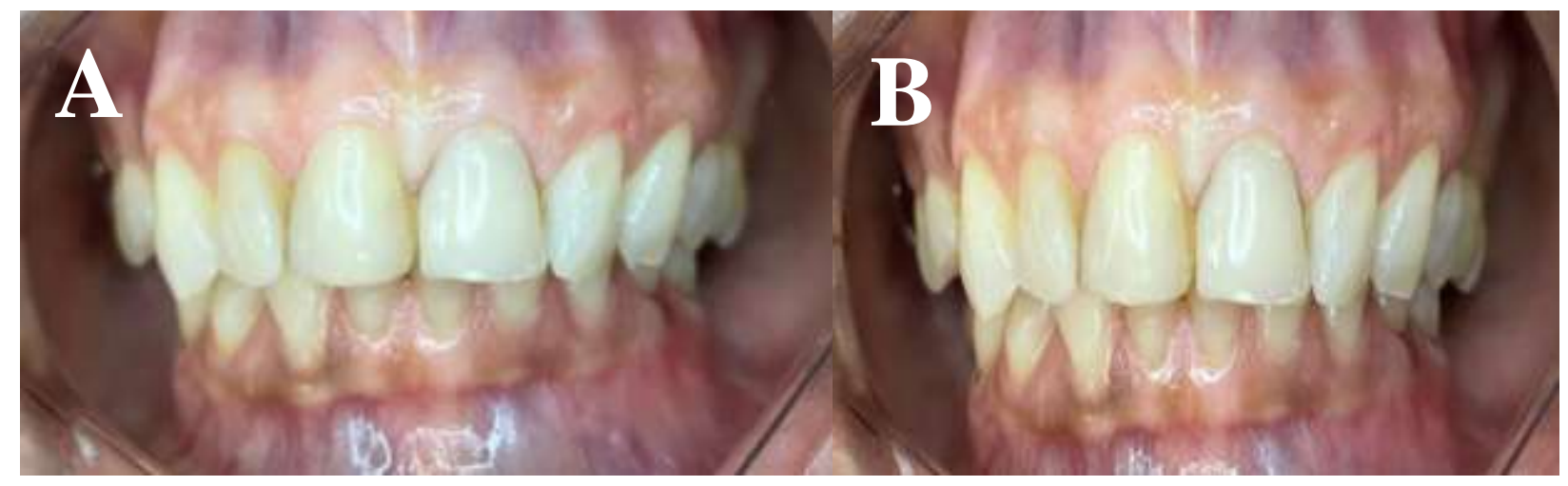

Fonte: Autores.

\section{Discussão}

Segundo Russo (2010), cuidados especiais devem ser tomados para restaurações unitárias quando os dentes recebem um tratamento endodôntico. Para dentes com grandes perdas de estrutura dentária, recomenda-se a utilização de retentores intrarradiculares para auxiliar na retenção de um núcleo ou restauração coronária (Vasconcelos et al.,2021).

Dentre as disponibilidades dos retentores intrarradiculares no mercado, os núcleos metálicos fundidos são indicados para condutos radiculares nos quais os pinos pré-fabricados não se adaptam corretamente às paredes, em dentes com pouco ou nenhum remanescente coronário, porém apresentam desvantagens que são a possibilidade de corrosão, módulo de elasticidade diferente da estrutura dental e possibilidade de fratura (Junior et al., 2020). Para Miorando et al., (2018), a restauração ideal de 
um dente deverá devolver a função, a estética e a preservação do remanescente dentário. Quando comparamos pinos de fibra de vidro e os metálicos fundidos, temos como vantagens nos pinos de fibra de vidro a diminuição do tempo clínico. Ao mesmo tempo, Leal et al., (2018) afirmam que, o pino de fibra de vidro é um material com características físicas, mecânicas e estéticas ideais ao remanescente dentário, apresentando biocompatibilidade, exigindo menor tempo clínico para sua confecção, não necessita da etapa laboratorial, preserva estrutura dentinária no preparo, valoriza a estética da reabilitação e tem menor custobenefício quando comparado com os outros tipos de retentores.

Para Camim et al., (2017) a má adaptação dos retentores pré-fabricado pino fibra de vidro em canais radiculares amplos, resulta em uma camada bastante espessa de cimento durante sua aplicação, gerando um grande volume de cimento resinoso, onde este é submetido ao processo de polimerização sob um alto fator de configuração cavitária (Fator-C) tornando desfavorável, com isso causando falhas nas ligações adesivas à dentina e ao pino de fibra de vidro por meio da contração de polimerização e consequentemente o estresse da interface cimento com a dentina, além da possibilidade de formação de bolhas, com isso diminuindo a resistência de união do cimento a estrutura dental (Khan et al.,2020). Vital et al., (2020) destacam que a utilização da forma tradicional dos pinos de fibra de vidro traz algumas desvantagens consideráveis como a deficiência de adaptação dos pinos frente a diferentes características anatômicas dos condutos radiculares. Para minimizar, Pegoraro (2014) cita como alternativa, em situações em que o espaço entre o pino e as paredes do conduto é acentuado, usar a técnica com pino acessório ou preenchimento do pino com resina composta, visando preencher o espaço e diminuir a espessura do cimento. A técnica de anatomização dos pinos de fibra de vidro é uma técnica promissora usada na reabilitação de dentes anteriores que passaram por tratamento endodôntico, em canais amplos, canais ovoides, que apresenta o dente fragilizado, com a técnica se consegue um retentor individualizado, com melhor adaptação e retenção dos pinos fibra de vidro sem precisar fazer desgaste desnecessário no dente, favorece a diminuição da linha de cimentação, imbricamento mecânico, promove menos risco de fraturas radiculares irreversíveis, além de proporcionar um bom resultado estético e maior conservação do remanescente dentário (Vital et al.,2020).

O sucesso do tratamento reabilitador de um dente fragilizado depende do comportamento mecânico de cada elemento envolvido na formação do conjunto, na combinação dentina-cimento-pino. A qualidade da adesão entre o cimento resinoso e a dentina radicular e pino podem ser afetados pelo tipo de cimento utilizado na obturação durante o tratamento endodôntico, estudos mostram melhores resultados de união quando combinado o cimento AH Plus com o cimento resinoso para cimentação do pino de fibra de vidro apresentando melhores resultados na adesão de cimento resinoso, visto que o cimento AH Plus é um selante à base de resina epóxi, possuem boas propriedades, proporciona excelente vedação apical e estabilidade dimensional (Coelho et al.,2020).

Ao comparar as vantagens e desvantagens dos tipos de cimentos quimicamente ativado e os fotopolimerizáveis na cimentação dos pinos, os cimentos resinosos de presa química garante uma polimerização, independente da profundidade de inserção do pino no conduto radicular. No entanto, possui características de manipulação inferior por não conseguir um controle do tempo de presa. Com isso os cimentos resinosos fotopolimerizáveis o processo de polimerização é realizado pela ativação de fotoiniciadores por meio da aplicação de luz, promovendo um maior controle do tempo para o assentamento do pino no interior do canal, remoção de excessos do material, porém possuem como limitação a polimerização em áreas com reduzido acesso à luz (Cardoso, 2020).

Para Henrique et al., (2018) quando comparado resistência à fratura, o uso do cimento resinoso autoadesivo apresenta forte adesão aos núcleos de resina composta associados aos pinos de fibra de vidro, proporcionando uma alternativa segura ao uso de retentores de metal fundido. Corroborando, Pereira et al., (2021) os cimentos resinosos autoadesivo apresentaram melhor força de ligação quando comparados com outros cimentos convencionais, não necessitando de prétratamento da dentina, pois combinam o uso do sistema adesivo ao cimento resinoso em uma única aplicação. No entanto, 
Léon et al., (2017) constataram nos seus estudos que não houve diferença significativa na resistência de união entre os dois sistemas cimentos resinosos utilizado RelyxTM ARC e Allcem quando comparam a resistência de união entre dentina radicular e pino pré-fabricado, poderão concluir que ambos os cimentos de resina são indicados na cimentação dos pinos de fibra de vidro. Júnior et al., (2021) evidenciaram que os cimentos autoadesivos passaram a ser a melhor opção de escolha para cimentação de pinos de fibra em vidro, promovendo uma melhor retenção, boa distribuição do estresse do elemento dentário além da melhor estética quando comparada aos demais materiais testados.

No presente caso clínico, optou-se pela utilização do retentor intrarradicular pino fibra de vidro por apresentar excelentes propriedades estéticas, físicas e mecânicas, comportamento elástico mais próximo ao dente, associada à técnica do pino anatomizado com resina composta, visando a preservação da estrutura do remanescente, a diminuição da linha de cimentação, proporcionando um menor volume de cimento e diminuição na contra polimerização do cimento nas paredes, melhorando a retenção do material restaurador final. Neste caso clínico para cimentação do pino anatômico, optou-se pelo cimento resinoso autoadesivo (Set PP SDI®) devido sua propriedade melhorada e simplificação das etapas operatória. A técnica mostrou ser alternativa, viável, segura, resolutiva e eficaz, na reabilitação do dente, obtendo um resultado satisfatório, onde foi devolvida a estética, função, forma do dente a cavidade oral. A paciente apresenta plena satisfação do resultado estético obtido.

\section{Conclusão}

Conclui-se que o uso do retentor intrarradicular do pino fibra de vidro é uma alternativa viável, resolutiva na reabilitação de dente comprometido, com grandes perdas estruturais, e que o protocolo com a técnica de anatomizar o pino com resina composta no conduto radicular tem sido eficaz na reabilitação deste dente, obtendo um resultado satisfatório.

\section{Referências}

Assunção, D. P. (2011). Pinos intrarradiculares pré-fabricados de fibra de vidro. Monografia (graduação). Unicamp.

Baratieri, L. N., et al. (2018). Odontologia restauradora: fundamentos e possibilidades. (2a ed.), Santos.

Barbosa, I. F., et al. (2016). Pinos de fibra: Revisão de Literatura. Revista Uningá Review, 28(1), 83-87.

Borges. D. M. C., \& Santos, R. A. (2019). Retentores intrarradiculares revisão de literatura. Trabalho de conclusão de curso (graduação), Universidade Uberaba.

Camim, F. da S., \& Maenosono, R. M. (2017). Avaliação da resistência a fratura de pinos de fibra de vidro cimentados com cimento resinoso de alto conteúdo de carga. Unifunec Científica Multidisciplinar, 5(7), 23-40. https://doi.org/10.24980/rfcm.v5i7.2335.

Cardoso, Wanessa Galmacci. (2020). Propriedades do pino de fibra de vidro e sua utilização clínica: Uma revisão de literatura. 22f. Unicesumar Universidade Cesumar.

Coelho, B. S., et al. (2020). Effects of 1-ethyl-3-(3-Dimethylaminopropyl) carbodiimide on adhesion of posts in teeth Obturated with Different sealers. Article. Braz.Dent.J. 31(4). https://doi.org/10.1590/0103-6440202002897

Henriques, P. A., et al. (2018). Fracture resistance of metal-ceramic Crown copings cemented to two types of intra-radiculares posts. Original Article. Rev. Odontol. UNESP 47 (5). https://doi.org/10.1590/1807-2577.09218.

Júnior, P. M. C., et al. (2021). Conventional versus resinous cements in fiberglass pin cementation: what is the best approach to follow in modern endodontics? A literature review. Brazilian Journal of Development, Curitiba, 7(6), 59652-59668. Doi:10.34117/bjdv7n6-381.

Junior, F. G. G., \& Cunha, M. H. D. (2020). Retentores metálico e não metálicos revisão de literatura, Uberaba -MG.

Khan Hosein, M., da Silva, K., \& de Pinho, L. (2020). Pino de fibra de vidro anatômico reembasado com resina composta em elementos dentários anteriores revisão de literatura. Revista Cathedral, 2(1). http://cathedral.ojs.galoa.com.br/index.php/cathedral/article/view/120

Khan Hosein, M., da Silva, K., \& de Pinho, L. (2020). Pino de fibra de vidro anatômico reembasado com resina composta em elementos dentários anteriores Revisão de literatura. Revista Cathedral, 2(1).

Leal, G. S., et al. (2018). Característica do pino de fibra de vidro e aplicações clínica: uma revisão de literatura. Id on Line Ver.Mult.Psic. 12(42), Supl.1, 1426. http://idonline.emnuvens.com/id 
Research, Society and Development, v. 10, n. 14, e52101421845, 2021

(CC BY 4.0) | ISSN 2525-3409 | DOI: http://dx.doi.org/10.33448/rsd-v10i14.21845

León, B. L. T., et al. (2017). Push-out bond strength of glass fiber posts luted with two resin cements. Brazilian Dental Science, 20(4), 78-84. 10.14295/bds. 2017. v20i4.1452.

Miorando, B., et al. (2018). Utilização de pinos intra-radiculares. Journal of Research in Dentistry 6(1), 16-22. http://dx.doi.org/10.19177/jrd.v6e1201816-22.

Pegoraro, L. F. (2014). Fundamentos de prótese fixa. São Paulo: artes Médicas, 160p.:il, color.:28cm. - (ABENO: Odontologia Essencial: parte clínica).

Pereira, J. R., et al. (2019). Push-out bond strength of fiberglass posts cemented with adhesive and self-adhesive resin cement according to the root canal surface. The Saudi Dental Journal, 33(1), 22-26. https://doi.org/10.1016/j.sdentj.

Pereira, A. S., Shitsuka, D. M., Parreira, F. J., \& Shitsuka, R. (2018). Metodologia da pesquisa científica. UFSM.

Russo, Eliza Maria Agueda. (2010). Dentistica: restaurações indiretas. 154p.:il, Fundamentos de odontologia. Santos.

Vasconcellos, A. C. A., et al. (2021). Avaliação Da Interferência Do Cimento Endodôntico Na Resistência De União De Um Cimento Resinoso À Dentina. Research, Society and Development, 10(7), e32810716583. http://dx.doi.org/10.33448/rsd-v10i7.16583

Vital, A. M., \& VitaL, K. G. B. M. (2020). O uso de pinos de fibra de vidro anatômicos em reabilitações de dentes anteriores: revisão de literatura. Monografia - Curso de Odontologia do Centro Universitário Fametro - Unifametro. 